Soapstock is a large-tonnage waste of the oil and fat industry, the disposal of which is environmentally hazardous. Processing of soapstock into industrially valuable products, in particular, fatty acids, is promising.

The method for producing fatty acids, which consists in sequential saponification of soapstock with sodium hydroxide solution, salting out with sodium chloride and decomposition with sulfuric acid solution has been investigated.

The feature of this work is the study of the effect of salting out conditions of saponified soapstock on the yield and neutralization number of fatty acids.

As an experimental sample, sunflower soapstock was used, the indicators of which correspond to DSTU 5033 (CAS 68952-95-4): mass fraction of total fat - $67.3 \%$, fatty acids $-61.8 \%$, neutral fat $-5.5 \%$.

Soapstock was subjected to preliminary saponification under the following conditions: duration 85 min., concentration of sodium hydroxide solution $45 \%$. After that, the saponified mass was subjected to salting out. The obtained core soap was decomposed with the sulfuric acid solution under the following conditions: temperature $90{ }^{\circ} \mathrm{C}$, duration 40 min.

Rational salting out conditions were determined: duration $(80$ min.) and sodium chloride concentration (16\%). Under these conditions, the fatty acid yield is $95.0 \%$, the neutralization number is $194.8 \mathrm{mg} \mathrm{KOH} / \mathrm{g}$. The resulting fatty acids comply with DSTU 4860 (CAS 61788-66-7): the mass fraction of moisture and volatiles is $0.85 \%$, the mass fraction of total fat is $98.9 \%$, cleavage depth is $94.2 \%$ oleic acid.

This method of soapstock processing increases the fatty acid yield by $3.5 \%$ compared to the method with saponification and decomposition, by $20.3 \%$ compared to the method of soapstock decomposition with sulfuric acid. At the same time, the neutralization number increases by $4.1 \%$ and $8.2 \%$, respectively.

The improved method for fatty acids producing from soapstock provides highquality fatty acids with increased yield

Keywords: fatty waste, soapstock, soap mass, salting out, fatty acids, neutralization number

$\square$
UDC 665.1

DOI: 10.15587/1729-4061.2021.245094

\section{DEVELOPMENT OF SOAPSTOCK PROCESSING TECHNOLOGY TO ENSURE WASTE-FREE AND SAFE PRODUCTION}

\author{
Viktoriia Kalyna \\ Corresponding author \\ $\mathrm{PhD}$, Associate Professor*
} E-mail: viktoriya-kalina@ukr.net Vitalii Koshulko $\mathrm{PhD}$, Associate Professor* OIha Ilinska $\mathrm{PhD}$

Department of Occupational and Environmental Safety** Natalia Tverdokhliebova $\mathrm{PhD}$

Department of Occupational and Environmental Safety** Oksana Tolstousova Senior Lecturer Department of Occupational and Environmental Safety**

Olga Bliznjuk

Doctor of Technical Sciences, Professor, Head of Department Department of Biotechnology, Biophysics and Analytical Chemistry**

Tatiana Gavrish

$\mathrm{PhD}$, Associate Professor, Head of Department Department of Technology of Bakery and Confectionery State Biotechnological University Alchevskykh str., 44, Kharkiv, Ukraine, 61002

Sergij Stankevych $\mathrm{PhD} * * *$

In a Zabrodina $\mathrm{PhD} * * *$

Oksana Zhulinska

$\mathrm{PhD}$

Cycle Commission Hotel and Restaurant Business Separate Structural Subdivision "Housing and Municipal Professional College" of O. M. Beketov National University of Urban Economy in Kharkiv

Shevchenko str., 233-A, Kharkiv, Ukraine, 61002

*Department of Technology of Storage and Processing of Agricultural Products

Dnipro State Agrarian and Economic University

Serhiya Yefremova str., 25, Dnipro, Ukraine, 49600 **National Technical University "Kharkiv Polytechnic Institute" Kyrpychova str., 2, Kharkiv, Ukraine, 61002 ***Department of Zoology, Entomology, Phytopathology, Integrated Plant Protection and Quarantine named after B. M. Litvinova State Biotechnological University Alchevskykh str., 44, Kharkiv, Ukraine, 61002
Received date 27.10.2021 Accepted date 29.11.2021 Published date 29.12.2021
How to Cite: Kalyna, V., Koshulko, V., Ilinska, O., Tverdokhliebova, N., Tolstousova, O., Bliznjuk, O., Gavrish, T., Stankevych, S. Zabrodina, I., Zhulinska, O. (2021). Development of soapstock processing technology to ensure waste-free and safe production. Eastern-European Journal of Enterprise Technologies, 6 (6 (114)), 23-29. doi: https://doi.org/10.15587/1729-4061.2021.245094

\section{Introduction}

Sunflower is one of the main oil crops in the world. Compared to other oil crops, sunflower gives the highest oil yield per unit area. The oil and fat industry is one of the most developed, as oils, fats and fat-containing products are widely used in various areas [1,2]. According to [3], the profitability level of sunflower seed production in agricul- 
tural enterprises in 2020 was $39.4 \%$, the highest among the main products.

The production of vegetable oil from sunflower seeds involves a number of by-products, namely: husk, cake, meal, phosphatide concentrate, soapstock, bleaching clays and others [4]. The main cause of environmental pollution is the openness of the resource cycle, which leads to the accumulation of waste [5]. Efficient processing of production waste is the key to production greening, provided by the introduction of the latest scientific research, energy-efficient resource-saving technologies, low-waste, waste-free technological processes. At the legislative level, these provisions are enshrined in international conventions, in particular the Stockholm Convention [6].

One of the large-tonnage wastes of vegetable oil production is soapstock - waste of the alkaline refining stage. The rate of soapstock formation is 0.1718 tons per ton of processed oil (according to Alfa Laval, Sweden) [7]. Soapstock is a valuable source of individual components (fats, fatty acids, soaps, phospholipids and other substances). Soapstock makes the largest share in the return waste of oil refining plants. The extraction of individual components during waste processing and the release of their commodity forms will provide additional resources of raw materials, reduce emissions into the environment and efficient use of natural resources [8]. An important area is the use of by-products and waste of fat production for the production of alternative diesel fuel [9]. Therefore, the improvement of soapstock processing technologies, the rational use of its composition and properties are one of the most relevant problems of the industry. The development of new solutions will increase the economic and environmental efficiency of production, reduce the anthropogenic burden on the environment.

\section{Literature review and problem statement}

Soapstock is a by-product of the neutralization stage of vegetable oils, which is a mixture of different valuable components that have limited use in combination [10]. Of particular value are fatty acids present in it, which are used in the production of soap, surfactants, biodiesel, etc. [11]. Depending on the characteristics of raw materials and concentration of alkali solution at the neutralization stage, the composition and properties of soapstock change. Soapstock treatment may include the separation of soap and fat by demulsification, followed by phase separation into fat and soap; conversion of triacylglycerols into fatty acids and salts. Various technologies have been developed to isolate fatty acids, in particular, soapstock decomposition with sulfuric acid; saponification and decomposition of the mixture, etc. The efficiency of the process lies in the percentage of extracted fatty acids and product quality.

In [9], data on the use of by-products and waste of fat production, in particular soapstock, for the production of alternative diesel fuel are presented. Various methods of soapstock pre-treatment for the separation of fatty acids are considered. One of the most effective was the method in which the soapstock sample was saponified, washed with salt solution and treated with acid. Further production of fatty acid esters, which are biodiesel, was investigated. Heterogeneous catalysts of iron sulfate and aluminum hydrogen phosphate cause a significant reduction in the final acid number and reduce the reaction time from 10 to 8 hours. However, the effect of soapstock treatment conditions on the quality and amount of fatty acids released, as well as the indicators of the obtained biodiesel fuel, is not shown.

According to [12], the technology of soapstock processing into biodiesel by methanolysis has been developed. It was found that the addition of tert-alcohol increases the yield of fatty acid methyl esters from $42.8 \%$ to $76.4 \%$. The yield of fatty acid methyl esters was further increased to $95.2 \%$ by optimizing the methanol/oil molar ratio, the amount of lipase and water-absorbing agent. The disadvantage of the study is the lack of data on methods for the effective separation of fatty acids from soapstock. After all, the yield and quality of esters depend on the quality and amount of fatty acids.

In [13], recommendations were developed for the allocation of soap raw material emulsion to restore the fat component from the waste of vegetable oil production. Extraction modes of the fat component during heating and introduction of various nonionic surfactants and electrolytes have been studied. The disadvantage of the study is the lack of data on the subsequent isolation of fatty acids from the fatty component of soapstock.

The authors of [14] note that an effective way to obtain fatty acids from soapstock is treatment with sulfuric acid. Rational conditions of soapstock treatment are determined: temperature $90-95{ }^{\circ} \mathrm{C}$, duration $40 \mathrm{~min}$. Under these conditions, the fatty acid yield is $79.0 \%$, the neutralization number is $180.0 \mathrm{mg} \mathrm{KOH} / \mathrm{g}$. Quality indicators of the obtained fatty acids: mass fraction of moisture and volatile substances $-1.8 \%$, mass fraction of total fat $-97.0 \%$, cleavage depth $-64.5 \%$ oleic acid, mineral acids - absent. This method of fatty acid isolation is effective, but research on increasing the fatty acid yield and development of new soapstock treatment methods are also advisable. There are no data on modern innovative methods for producing high-quality fatty acids.

In [15], the results of soap production from soapstocks are given. It is determined that dehydration of soapstocks is necessary to improve the quality of finished products. The number of cleaning stages by salting out increases the volume of soapy alkali formation. But there is no information on the possibility and effectiveness of further production of fatty acids.

In [16], the fatty acid production from soapstock by hydrolysis was investigated. The enzymatic catalysts achieved a maximum conversion of $70 \%$. The disadvantage of the study is the lack of the effect of hydrolysis conditions on the quality of the obtained fatty acids.

The authors [17] proposed a method of soapstock concentration by salting out. Due to the separation of the aqueous layer, the concentration of the target substance is doubled. Sulfuric acid treatment of soapstock allows isolating a concentrate of fats and higher fatty acids, which can be used as an effective feed additive. The disadvantage of the study is the lack of information on the effect of salting out conditions on the efficiency of fatty acid extraction (yield and quality).

A promising technology is the processing of soapstock into fatty acids by saponification and subsequent salting out to increase the efficiency of fatty acid extraction. According to the literature data $[9,12-17]$, there is little information on the relationship between the salting out conditions of saponified soapstock and the yield and quality of fatty acids. Thus, research to determine rational conditions for fatty acid production from soapstock, including the stages of saponifi- 
cation, salting out and decomposition with sulfuric acid, is an urgent scientific task.

\section{The aim and objectives of the study}

The aim of the study is to improve the technology of fatty acid production from soapstock. This will provide fatty acids with improved quality and yield using the soapstock treatment method involving pre-saponification, salting out and decomposition with sulfuric acid solution.

To achieve the aim, the following objectives were accomplished:

- to determine the quality of the experimental sunflower soapstock sample;

- to determine the relationship between the salting out conditions of saponified soapstock and the yield and neutralization number of fatty acids and determine rational salting out conditions;

- to determine organoleptic, physicochemical parameters and composition of the obtained fatty acids and compare with the corresponding indicators of fatty acids obtained by different methods.

\section{Research materials and methods}

\section{1. Examined materials and equipment used in the} experiment

The following reagents and materials were used:

- sodium hydroxide, analytical grade, according to acting regulatory documentation;

- sulfuric acid, analytical grade, according to GOST 4204 (CAS 7664-93-9);

- sodium chloride, analytical grade, according to acting regulatory documentation.

4. 2. Procedure for determining the quality indicators of the experimental sunflower soapstock sample

Organoleptic indicators of soapstock are determined by standard methods according to DSTU 5033:2008 (Method for determining color, consistency and odor). International regulatory documents for determining organoleptic parameters: color - ISO 15305, consistency - AOCS Method Cc 16-60, odor - AOCS Cg 2-83. The mass fraction of moisture is determined by the standard method according to DSTU 4603:2006 (ISO 662). The mass fraction of total fat and fatty acids is determined by the standard method according to DSTU 5033:2008 (ISO 17189, IDF 194).

\section{3. Soapstock treatment procedure}

Preliminary soapstock saponification was performed according to [18]. A portion of saponified soapstock was placed in a heat-resistant flask mounted on an electric stove. Dry sodium chloride was added in the amount provided in the experimental plan. The resulting viscous mass was mixed thoroughly, then water with a temperature of $60{ }^{\circ} \mathrm{C}$ was added in an amount of $50 \%$ by weight of soapstock. The salting out was carried out for the time provided in the experimental plan, under conditions of boiling and stirring. The resulting mass was settled for 2 hours. The mass was divided into three layers - lower (soapy alkali), middle (glue soap), upper - core soap. The core soap was further treated with sulfuric acid according to [16].
4. 4. Procedure for determining the quality and composition of fatty acids

The neutralization number of fatty acids is determined as follows. A portion of fatty acids of about $2.0 \mathrm{~g}$ is dissolved in $40-60 \mathrm{~cm}^{3}$ of ethyl alcohol. Add $0.5 \mathrm{~cm}^{3}$ of phenolphthalein solution and titrate with $0.5 \mathrm{~N}$ aqueous or alcoholic solution of potassium hydroxide to a pink color that does not disappear within 30 seconds. The neutralization number $(\mathrm{NN})$ is calculated:

$$
N N=\frac{V \cdot 28.05 \cdot K}{P},
$$

where $V$ is the amount, $\mathrm{cm}^{3}$, of $0.5 \mathrm{~N}$ potassium hydroxide solution used for titration; 28.05 - titer of exactly $0.5 \mathrm{~N}$ potassium hydroxide solution multiplied by 1000 ;

$K$ - correction to a titer of $0.5 \mathrm{~N}$ potassium hydroxide solution;

$P$ - weight of fatty acids, g. Organoleptic indicators, mass fraction of total fat, cleavage depth, presence of mineral acids are determined by standard methods according to DSTU 4860: 2007, mass fraction of moisture - according to DSTU 4603: 2006. Fatty acid composition is determined by standard methods according to DSTU ISO 5508-2001 and DSTU ISO 5509-2002.

\section{5. Research planning and results processing}

The second-order full factorial experiment was used for research planning and mathematical data processing. Processing of scientific results, construction of graphical dependences were performed in the Stat Soft Statistica v6.0 (USA) environment. Each experiment was performed twice.

\section{Results of studying the effect of saponified soapstock salting out conditions on the yield and neutralization number of fatty acids}

5. 1. Determination of quality indicators of the experimental sample of sunflower soapstock

The determined organoleptic and physicochemical indicators of the experimental sample of sunflower soapstock are given in Table 1.

Table 1

Quality indicators of soapstock

\begin{tabular}{|c|c|}
\hline Indicator & Characteristic \\
\hline \multicolumn{2}{|c|}{ Organoleptic indicators } \\
\hline Color & Light brown \\
\hline Consistency at $20{ }^{\circ} \mathrm{C}$ & Oily \\
\hline Odor & $\begin{array}{c}\text { Characteristic of sunflower oil } \\
\text { soapstock }\end{array}$ \\
\hline \multicolumn{2}{|c|}{ Physicochemical indicators } \\
\hline $\begin{array}{c}\text { Mass fraction of moisture and } \\
\text { volatile substances, \% }\end{array}$ & 15.9 \\
\hline Mass fraction of total fat, \% & 67.3 \\
\hline Mass fraction of fatty acids, $\%$ & 61.8 \\
\hline Mass fraction of neutral fat, \% & 5.5 \\
\hline
\end{tabular}

In terms of quality indicators, the experimental sample of sunflower soapstock corresponds to DSTU 5033 (CAS 68952-95-4). 
5. 2. Determining the relationship between salting out conditions and the yield and neutralization number of fatty acids

The method of soapstock treatment involving pre-saponification, salting out (to obtain core soap) and decomposition with sulfuric acid solution was investigated. Preliminary soapstock saponification was performed according to [18]: duration 85 minutes, concentration of sodium hydroxide solution $45 \%$. Decomposition of core soap with sulfuric acid was performed according to [14]: temperature $90-95{ }^{\circ} \mathrm{C}$, duration $40 \mathrm{~min}$. The effect of salting out conditions on the yield and neutralization number of fatty acids was determined. Experimental conditions: number of factors -2 , number of variation levels of factors -5 , number of experiments -25 . Factors and intervals of variation:

$x_{1}$ - concentration of dry sodium chloride: from 6 to $18 \%(6,9,12,15,18 \%)$;

$x_{2}$ - duration of salting out: from 30 to $90 \mathrm{~min}$. (30, 45, 60, 75, 90 min.).

The response functions are the yield ( $\%$ of the available fatty acid content in soapstock) and the neutralization number of fatty acids obtained by the improved technology (saponification, salting out and decomposition with sulfuric acid). Table 2 shows the experiment planning matrix, experimental and calculated values of response functions.

Table 2

Planning matrix, experimental and calculated values of response functions

\begin{tabular}{|c|c|c|c|c|c|c|}
\hline \multirow[b]{2}{*}{$\begin{array}{l}\text { Exper- } \\
\text { iment } \\
\text { num- } \\
\text { ber }\end{array}$} & \multicolumn{2}{|c|}{$\begin{array}{l}\text { Factors of vari- } \\
\text { ation }\end{array}$} & \multicolumn{2}{|c|}{$\begin{array}{l}\text { Experimental values } \\
\text { of response functions }\end{array}$} & \multicolumn{2}{|c|}{$\begin{array}{l}\text { Calculated values of } \\
\text { response functions }\end{array}$} \\
\hline & $\begin{array}{c}\text { Sodium } \\
\text { chloride } \\
\text { con- } \\
\text { centra- } \\
\text { tion, } \%\end{array}$ & $\begin{array}{c}\text { Salting } \\
\text { out du- } \\
\text { ration, } \\
\text { min }\end{array}$ & Yield, \% & $\begin{array}{c}\text { Neutral- } \\
\text { ization } \\
\text { number, } \\
\text { mg KOH/g }\end{array}$ & Yield, \% & $\begin{array}{c}\text { Neutral- } \\
\text { ization } \\
\text { number, } \\
\text { mg KOH/g }\end{array}$ \\
\hline 1 & 6 & 30 & 56.1 & 105.1 & 61.7 & 106.5 \\
\hline 2 & 6 & 45 & 57.8 & 119.5 & 63.1 & 117.4 \\
\hline 3 & 6 & 60 & 63.1 & 131.0 & 67.4 & 126.3 \\
\hline 4 & 6 & 75 & 77.5 & 135.1 & 74.6 & 133.3 \\
\hline 5 & 6 & 90 & 92.7 & 136.8 & 84.7 & 138.3 \\
\hline 6 & 9 & 30 & 60.0 & 107.1 & 62.3 & 116.0 \\
\hline 7 & 9 & 45 & 59.8 & 122.8 & 63.6 & 126.9 \\
\hline 8 & 9 & 60 & 65.4 & 136.7 & 67.9 & 135.8 \\
\hline 9 & 9 & 75 & 81.0 & 135.4 & 75.1 & 142.8 \\
\hline 10 & 9 & 90 & 94,1 & 141.8 & 85.3 & 147.8 \\
\hline 11 & 12 & 30 & 70.9 & 134.1 & 65.9 & 129.9 \\
\hline 12 & 12 & 45 & 71.5 & 145.9 & 67.2 & 140.8 \\
\hline 13 & 12 & 60 & 72.4 & 155.8 & 71.5 & 149.7 \\
\hline 14 & 12 & 75 & 78.9 & 167.1 & 78.7 & 156.7 \\
\hline 15 & 12 & 90 & 85.5 & 177.5 & 88.8 & 161.7 \\
\hline 16 & 15 & 30 & 71.8 & 141.1 & 72.5 & 148.1 \\
\hline 17 & 15 & 45 & 75.2 & 150.0 & 73.8 & 159.0 \\
\hline 18 & 15 & 60 & 75.8 & 160.1 & 78.1 & 167.9 \\
\hline 19 & 15 & 75 & 79.9 & 168.5 & 85.3 & 174.9 \\
\hline 20 & 15 & 90 & 87.1 & 180.0 & 95.5 & 179.9 \\
\hline 21 & 18 & 30 & 85.5 & 183.2 & 82.1 & 170.7 \\
\hline 22 & 18 & 45 & 88.7 & 187.5 & 83.5 & 181.5 \\
\hline 23 & 18 & 60 & 91.4 & 190.0 & 87.5 & 190.4 \\
\hline 24 & 18 & 75 & 95.9 & 194.1 & 95.0 & 197.4 \\
\hline 25 & 18 & 90 & 98.5 & 195.8 & 105.1 & 202.4 \\
\hline
\end{tabular}

In the Stat Soft Statistica v6.0 package (USA), mathematical models (second-order regression equations) were obtained, which are dependences of response functions on salting out conditions. The response functions are marked as follows:

$-y_{1}-$ yield, \%;

$-y_{2}-$ neutralization number of fatty acids, $\mathrm{mg} \mathrm{KOH} / \mathrm{g}$.

The regression dependence of the fatty acid yield on salting out conditions in real variables has the form:

$$
\begin{aligned}
& y_{1}=47.88-0.02 \cdot x_{1}+0.07 \cdot x_{2}+ \\
& +0.17 \cdot x_{1}^{2}-0.04 \cdot x_{1} \cdot x_{2}+0.01 \cdot x_{2}^{2}
\end{aligned}
$$

The regression dependence of the neutralization number of fatty acids on salting out conditions in real variables has the form:

$$
\begin{aligned}
& y_{1}=60.09+0.63 \cdot x_{1}+1.26 \cdot x_{2}+ \\
& +0.24 \cdot x_{1}^{2}-0.02 \cdot x_{1} \cdot x_{2}-0.004 \cdot x_{2}^{2} .
\end{aligned}
$$

The adequacy of the mathematical models was confirmed by the level of significance of the equation coefficients $(p>0.05)$ and the values of the determination coefficients ( 0.925280 and 0.966926 for yield and neutralization number, respectively). The graphical dependences of the response functions on salting out conditions (response surface) are shown in Fig. 1, 2.

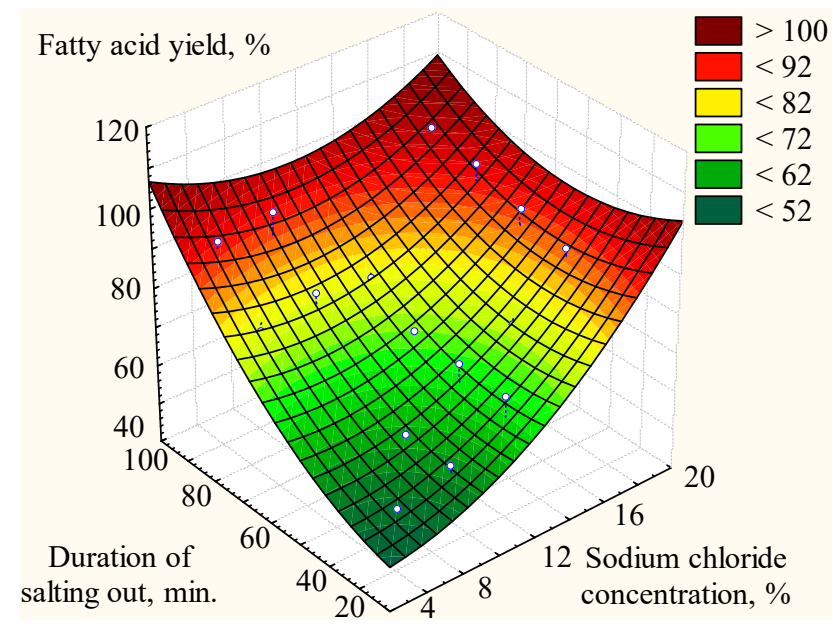

Fig. 1. Dependence of fatty acid yield on salting out duration and sodium chloride concentration

Analysis of Table 2, equation (2) and Fig. 1 found that salting out duration has a greater effect on fatty acid yield than sodium chloride concentration. The highest acid yields are observed starting from the salting out duration of $80 \mathrm{~min}$. and sodium chloride concentration of $16 \%$. A further increase in the values of the factors does not significantly increase the values of the response functions. In this case, the fatty acid yield is $95.0 \%$.

According to Table 2, equation (3) and Fig. 2, an increase in sodium chloride concentration has a greater effect on the neutralization number of fatty acids than an increase in salting out duration. The highest values and a gradual decrease in the increase of the neutralization number are observed starting from the salting out duration of 75-80 min. and sodium chloride concentration of $16-17 \%$. Therefore, the following salting out conditions are rational: duration $80 \mathrm{~min}$, 
sodium chloride concentration $16 \%$. Under these conditions, the neutralization number was $194.8 \mathrm{mg} \mathrm{KOH} / \mathrm{g}$.

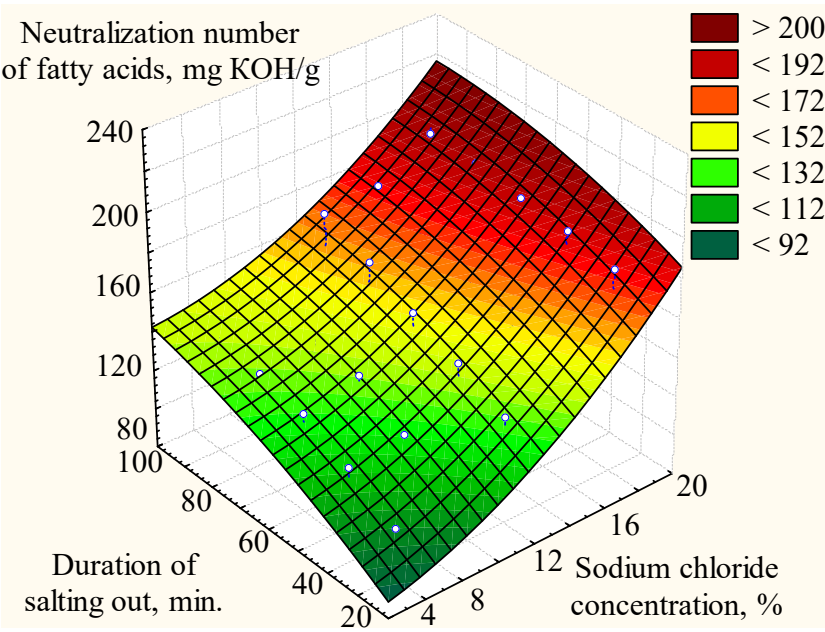

Fig. 2. Dependence of neutralization number of fatty acids on salting out duration and sodium chloride concentration

\section{3. Comparative analysis of quality in-} dicators of fatty acids obtained by different methods

In [14], the first method of fatty acids obtaining was investigated - only by soapstock treatment with sulfuric acid. Under rational conditions (temperature $90{ }^{\circ} \mathrm{C}$, duration $40 \mathrm{~min}$.), the fatty acid yield was $79.0 \%$, the neutralization number - $180.0 \mathrm{mg} \mathrm{KOH} / \mathrm{g}$. In [18], the second method of fatty acids obtaining from soapstock was investigated - by saponification and decomposition with sulfuric acid. Under rational conditions (duration $85 \mathrm{~min}$., concentration of sodium hydroxide solution $45 \%$ ), the yield of fatty acids was $91.8 \%$, the neutralization number $-187.1 \mathrm{mg} \mathrm{KOH} / \mathrm{g}$.

The method of soapstock treatment with salting out allows increasing the fatty acid yield by $3.5 \%$ compared to the second method (saponification and decomposition). The yield increases by $20.3 \%$ compared to the first method (soap- stock decomposition with sulfuric acid). The neutralization number increased by $4.1 \%$ and $8.2 \%$, respectively. Fig. 3 shows comparative data on fatty acids obtained by different methods. The characteristics of fatty acids obtained by the first and second methods are given in accordance with $[14,18]$.

The fatty acids obtained by all three methods have a brown color at a temperature of $20^{\circ} \mathrm{C}$, the odor is specific for fatty acids. No mineral acids are present in all the samples.

According to Fig. 3, with the inclusion of the salting out step, fatty acids, corresponding to the characteristics of fatty acids of light oils and modified fats obtained with saponification, of the first grade according to DSTU 4860 (CAS 61788-66-7) were obtained. The acids obtained with salting out have a much lower mass fraction of moisture and volatile substances. The method with saponification and decomposition with sulfuric acid allowed increasing the cleavage depth by only $7.3 \%$. The salting out method increased this indicator by $46.0 \%$ compared to the first method and by $36.1 \%$ compared to the second method.

Table 3 shows the composition of fatty acids obtained by different methods. The composition of fatty acids obtained by the first and second methods and sunflower oil is presented according to $[14,18]$.

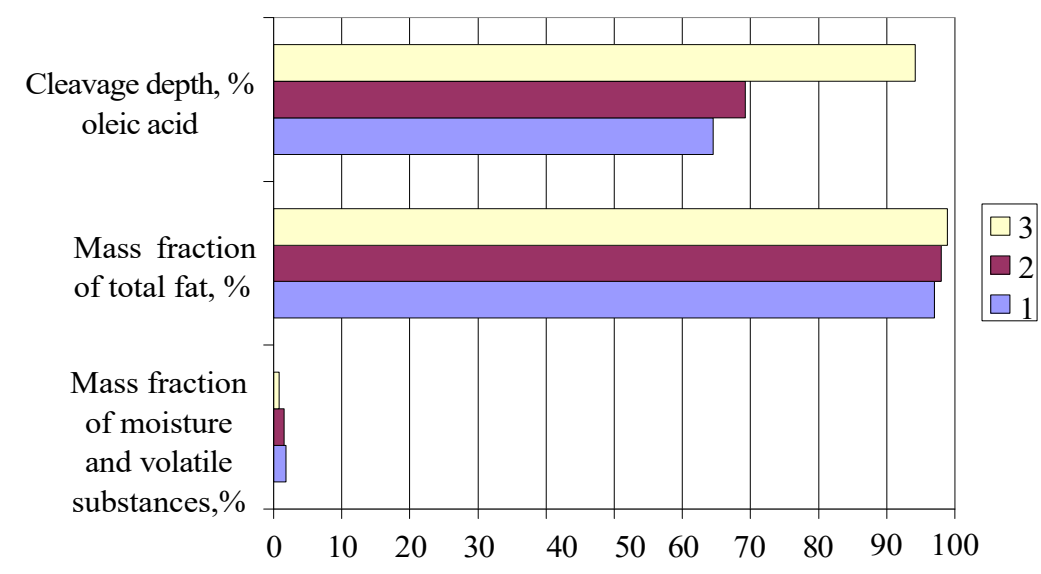

Fig. 3. Physicochemical indicators of fatty acids obtained by different methods: 1 - fatty acids obtained by decomposition with sulfuric acid; 2 - fatty acids obtained by saponification and decomposition with sulfuric acid; 3 - fatty acids obtained by saponification, salting out and decomposition with sulfuric acid

Table 3

Composition of fatty acids and fatty acid composition of sunflower oil

\begin{tabular}{|c|c|c|c|c|c|}
\hline \multirow{2}{*}{ No. } & Fatty acid & $\begin{array}{c}\text { Sunflow- } \\
\text { er oil }\end{array}$ & $\begin{array}{c}\text { Fatty acids obtained by de- } \\
\text { composition with sulfuric acid }\end{array}$ & $\begin{array}{c}\text { Fatty acids obtained by saponi- } \\
\text { fication and decomposition with } \\
\text { sulfuric acid }\end{array}$ & $\begin{array}{c}\text { Fatty acids obtained by saponification, } \\
\text { salting out and decomposition with } \\
\text { sulfuric acid }\end{array}$ \\
\hline 1 & Palmitic $\mathrm{C}_{16: 0}$ & 1.7 & 0 & 1.0 & 1.2 \\
\hline 2 & Palmitoleic $\mathrm{C}_{16: 1}$ & 0.2 & 0.7 & 0.4 & 0.4 \\
\hline 3 & Stearic $\mathrm{C}_{18: 0}$ & 3.6 & 6.9 & 6.0 & 5.5 \\
\hline 4 & Oleic $\mathrm{C}_{18: 1}$ & 30.9 & 37.4 & 35.4 & 33.5 \\
\hline 5 & Linoleic $\mathrm{C}_{18: 2}$ & 62.3 & 51.2 & 54.8 & 0 \\
\hline 6 & Linolenic $\mathrm{C}_{18: 3}$ & 0.1 & 0 & 0 & 0.4 \\
\hline 7 & Arachinic $\mathrm{C}_{20: 0}$ & 0.2 & 0.4 & 0.4 & 0.3 \\
\hline 8 & Gadoleic $\mathrm{C}_{20: 1}$ & 0.1 & 0.8 & 0.3 & 0.9 \\
\hline 9 & Behenic $\mathrm{C}_{22: 0}$ & 0.7 & 1.2 & 0.9 & 0.3 \\
\hline 10 & Lignoceric $\mathrm{C}_{24: 0}$ & 0.2 & 0.4 & 0.3 & 0.5 \\
\hline 11 & Myristic $\mathrm{C}_{14: 0}$ & 0 & 1.0 & 0.5 & 100.0 \\
\hline
\end{tabular}


Analysis of Table 3 indicates that in terms of the concentration of basic fatty acids (stearic, oleic, linoleic), the acids obtained by salting out correspond more to sunflower oil acids than those obtained by other methods.

\section{Discussion of the results of studying the relationship between salting out conditions and the yield and neutralizations number of fatty acids}

The improved technology for fatty acids obtaining from soapstock, including the stages of saponification, salting out and decomposition with sulfuric acid, has been studied. The inclusion of the salting out stage increases the yield and neutralization number of fatty acids. This is due to the fact that the salting out process maximizes the concentration of the soap component of soapstock, obtained after pre-saponification. The purified and concentrated core soap is then subjected to decomposition with sulfuric acid, resulting in the formation of high-quality fatty acids.

The effect of salting out conditions of saponified soapstock on the yield and neutralization number of fatty acids is determined. The work is a continuation of the studies $[14,18]$ considering the extraction of fatty acids in one stage (decomposition with sulfuric acid) and in two stages (saponification and decomposition), respectively. In the first case, under rational conditions, the yield of fatty acids was $79.0 \%$, the neutralization number was $180.0 \mathrm{mg} \mathrm{KOH} / \mathrm{g}$ [14]. In the second case, under rational conditions, the yield of fatty acids was $91.8 \%$, the neutralization number was $187.1 \mathrm{mg} \mathrm{KOH} / \mathrm{g}$ [18]. The method of soapstock treatment involving the salting out stage increases the yield of fatty acids by $3.5 \%$ compared to the second method (with saponification and decomposition). At the same time, the yield increases by $20.3 \%$ compared to the first method (decomposition with sulfuric acid). The neutralization number increases by $4.1 \%$ and $8.2 \%$, respectively.

Analysis of quality indicators of fatty acids obtained by different methods shows that the salting out stage improves the quality of fatty acids. The acids have a much lower mass fraction of moisture and volatile substances, as well as an increased cleavage depth. The method with saponification and decomposition with sulfuric acid increased the cleavage depth by only $7.3 \%$. The salting out process increased this indicator by $46.0 \%$ compared to the first method (sulfuric acid decomposition) and by $36.1 \%$ compared to the second method (saponification and decomposition). The corresponding data are shown in Fig. 3.

The work differs from existing [9,12-17] scientific research by the development of the improved technology, which provides fatty acids with the maximum yield and neutralization number. Such acids have improved quality.

Salting out is widely used in the production of soap, which is sodium or potassium salts of fatty acids. For example, the main component of soap is sodium stearate, and its salting out is carried out with sodium chloride. This results in the product of stearate ion and sodium ion concentrations being greater than the solubility product of sodium stearate. In this case, salting out is due to the effect of the total ion, the role of which is played by the sodium ion $\mathrm{Na}+$. Electrolytes, in particular sodium chloride, when dissolved in water, reduce the solubility of soap. The homogeneity of soap glue is disturbed. The difference between the proportion of soap and sodium chloride solution causes the soap, as lighter, to separate and float, forming a layer of concentrated, so-called core soap. Salting out is promising in terms of use in the separation of fatty acids from soapstocks.

Increasing the process duration and concentration of dry sodium chloride increases the yield and neutralization number of acids by intensifying the salting out process and increasing the solution density (Table 2, Fig. 1, 2). For the process duration of $30 \mathrm{~min}$. with an increase in sodium chloride concentration from 6 to $18 \%$, the yield increases 1.5 times, the neutralization number -1.7 times. With a sodium chloride concentration of $6 \%$, as a result of increasing the duration from 30 to $90 \mathrm{~min}$., the acid yield increases 1.7 times, the neutralization number - 1.3 times. Increasing sodium chloride concentration has a greater effect on the neutralization number, and increasing the salting out duration - on the yield of fatty acids. The highest acid yields are observed starting from the salting out duration of $80 \mathrm{~min}$. and sodium chloride concentration of $16 \%$ (Table 2 , equation (2), Fig. 1). The highest values and a gradual decrease in the increase of the neutralization number are observed starting from the salting out duration of $75-80 \mathrm{~min}$. and sodium chloride concentration of 16-17\% (Table 2, equation (3), Fig. 2). Therefore, the following salting out conditions are rational: duration $80 \mathrm{~min}$., sodium chloride concentration $16 \%$. Under these conditions, the yield of fatty acids is $95.0 \%$, the neutralization number $-194.8 \mathrm{mg} \mathrm{KOH} / \mathrm{g}$. Thus, pre-saponification of soapstock allows more complete conversion of the fat component into soap, salting out allows maximum concentration and isolation of the soap component, which is subjected to decomposition with sulfuric acid. The obtained data significantly expand the possibilities of using soapstock to obtain fatty acids and determine the relationship between the conditions of soapstock salting out and efficiency of acid extraction. The results of the work are a scientific basis for solving the problem of waste disposal and intensifying the process of obtaining fatty acids from soapstocks. The use of the obtained results in production requires observance of rational conditions of soapstock treatment and purity of reagents. An additional stage of soapstock treatment (salting out) can lead to additional loss of the fat component of the soapstock. To reduce and avoid losses, it is necessary to ensure necessary settling duration and phase separation efficiency after salting out and washing of the final fatty acids from sulfuric acid residues.

The disadvantage of the study is that it determined the effect of soapstock treatment conditions only on the quality and yield of fatty acids. It is also advisable to show how soapstock treatment conditions affect the quality of biodiesel fuel derived from fatty acids. Promising areas of research are to determine a wider range of fatty acids indicators (saponification number, ether number, phase transition parameters, etc.). This will allow a more detailed analysis of the effect of different methods of soapstock treatment on the composition, quality and amount of fatty acids, as well as the possibility of their use in different directions.

\section{Conclusions}

1. Quality indicators of experimental sunflower soapstock are determined: mass fraction of total fat $-67.3 \%$, fatty acids $-61.8 \%$, neutral fat $-5.5 \%$. The compliance of soapstock with the requirements of DSTU 5033 (CAS 68952-95-4) has been found. 
2. The relationship between the salting out conditions of saponified soapstock and the yield and neutralization number of fatty acids was determined. By the corresponding regression dependences, rational salting out conditions were determined: duration (80 min.) and sodium chloride concentration $(16 \%)$. Under these conditions, the yield of fatty acids is $95.0 \%$, the neutralization number $-194.8 \mathrm{mg} \mathrm{KOH} / \mathrm{g}$.

3 . The comparative analysis of the composition and quality of fatty acids obtained by different methods was performed. The method of soapstock treatment involving salting out increases the yield of fatty acids by $20.3 \%$ compared to the first method (soapstock decomposition with sulfuric acid). The yield increases by $3.5 \%$ compared to the second method (with saponification and decomposition). The neutralization number increases by $8.2 \%$ and $4.1 \%$, respectively. The acids obtained with salting out have a much lower mass fraction of moisture and volatile substances, as well as a significantly increased cleavage depth. The method with saponification and decomposition with sulfuric acid allowed increasing the depth of acid cleavage by only $7.3 \%$. The salting out method increased this indicator by $46.0 \%$ compared to the first method and by $36.1 \%$ compared to the second method. In terms of the concentration of basic fatty acids (stearic, oleic, linoleic), the acids obtained with salting out correspond more to sunflower oil acids than those obtained by other methods.

\section{References}

1. Vasylkovska, K. (2021). Tendentsiyi ta perspektyvy vyrobnytstva oliinykh kultur v Ukraini y analiz eksportu oliyi. Ahrobiznes sohodni. Available at: http://agro-business.com.ua/agro/ekonomichnyi-hektar/item/20517-tendentsii-ta-perspektyvyvyrobnytstva-oliinykh-kultur-v-ukraini-i-analiz-eksportu-olii.html

2. Krukov, A. I., Radchenko, O. V., Radchenko, O. O., Garmash, B. K., Biletska, Ye. S., Ponomarenko, R. V. et. al. (2020). Experience of developed countries in state environmental safety policy. Ukrainian Journal of Ecology, 10 (2), 190-194. Available at: https:// www.ujecology.com/articles/experience-of-developed-countries-in-environmental-safety-policy.pdf

3. Instytutu ahrarnoi ekonomiky. Available at: https://latifundist.com/kompanii/1928-institut-agrarnoj-ekonomiki

4. Yegorov, B., Turpurova, T., Sharabaeva, E., Bondar, Y. (2019). Prospects of using by-products of sunflower oil production in compound feed industry. Food Science and Technology, 13 (1), 106-113. doi: https://doi.org/10.15673/fst.v13i1.1337

5. Osman, A. I., Mehta, N., Elgarahy, A. M., Al-Hinai, A., Al-Muhtaseb, A. H., Rooney, D. W. (2021). Conversion of biomass to biofuels and life cycle assessment: a review. Environmental Chemistry Letters, 19 (6), 4075-4118. doi: https://doi.org/10.1007/ s10311-021-01273-0

6. Hodovaniuk, A. Y. (2010). Pravovyi vplyv na vprovadzhennia malovidkhodnykh tekhnolohiy, enerhozberihaiuchoi tekhniky ta vyrobnytstvo bezpechnoi produktsiyi. Aktualni problemy polityky, 40, 583-588. Available at: http://dspace.onua.edu.ua/ handle/11300/1042

7. Alfa Laval. Available at: https://www.alfalaval.com/

8. Bessou, C., Ferchaud, F., Gabrielle, B., Mary, B. (2011). Biofuels, greenhouse gases and climate change. A review. Agronomy for Sustainable Development, 31 (1), 1-79. doi: https://doi.org/10.1051/agro/2009039

9. Demidov, I., Sytnik, N., Mazaeva, V. (2014). Sunflower and problem alternative fuel in Ukraine. Naukovo-tekhnichnyi biuleten Instytutu oliinykh kultur NAAN, 21, 137-146. Available at: http://nbuv.gov.ua/UJRN/znpiok_2014_21_22

10. Barbusiński, K., Fajkis, S., Szeląg, B. (2021). Optimization of soapstock splitting process to reduce the concentration of impurities in wastewater. Journal of Cleaner Production, 280, 124459. doi: https://doi.org/10.1016/j.jclepro.2020.124459

11. Laoretani, D. S., Fischer, C. D., Iribarren, O. A. (2017). Selection among alternative processes for the disposal of soapstock. Food and Bioproducts Processing, 101, 177-183. doi: https://doi.org/10.1016/j.fbp.2016.10.015

12. Su, E., Wei, D. (2014). Improvement in biodiesel production from soapstock oil by one-stage lipase catalyzed methanolysis. Energy Conversion and Management, 88, 60-65. doi: https://doi.org/10.1016/j.enconman.2014.08.041

13. Poyarkova, T. N., Kudrina, G. V., Prokof'ev, Y. I. (2012). Effect of inorganic electrolytes and nonionogenic surfactants on the stability of soap stock emulsion. Russian Journal of Applied Chemistry, 85 (4), 651-655. doi: https://doi.org/10.1134/s1070427212040192

14. Sytnik, N., Kunitsia, E., Mazaeva, V., Kalyna, V., Chernukha, A., Vazhynskyi, S. et. al. (2021). Rational conditions of fatty acids obtaining by soapstock treatment with sulfuric acid. Eastern-European Journal of Enterprise Technologies, 4 (6 (112)), 6-13. doi: https://doi.org/10.15587/1729-4061.2021.236984

15. Chupa, J., Misner, S., Sachdev, A., Wisniewski, P., Smith, G. A., Heffner, R. (2017). Soap, Fatty Acids, and Synthetic Detergents. Handbook of Industrial Chemistry and Biotechnology, 979-1032. doi: https://doi.org/10.1007/978-3-319-52287-6_16

16. Casali, B., Brenna, E., Parmeggiani, F., Tessaro, D., Tentori, F. (2021). Enzymatic Methods for the Manipulation and Valorization of Soapstock from Vegetable Oil Refining Processes. Sustainable Chemistry, 2 (1), 74-91. doi: https://doi.org/10.3390/ suschem2010006

17. Shnyp, I. A., Slepneva, L. M., Kraeckaya, O. F., Zyk, N. V., Luk'yanova, R. S. (2011). Sposoby utilizacii soapstoka - tehnogennogo othoda zhiropererabatyvayuschey promyshlennosti. Vestnik Belorusskogo nacional'nogo tehnicheskogo universiteta, 2, 68-71. Available at: https://rep.bntu.by/bitstream/handle/data/1079/68-71.pdf?sequence=1\&isAllowed=y

18. Sytnik, N., Kunitsia, E., Kalyna, V., Petukhova, O., Ostapov, K., Ishchuk, V. et. al. (2021). Technology development of fatty acids obtaining from soapstok using saponification. Eastern-European Journal of Enterprise Technologies, 5 (6 (113)), 16-23. doi: https://doi.org/10.15587/1729-4061.2021.241942 